\title{
Faktor untuk Meningkatkan Inovasi di Negara Berkembang - Tinjauan Literatur Sistematis
}

\author{
Muhammad Rifqi Arviansyah \\ Universitas Padjadjaran \\ Jl. Raya Bandung - Sumedang Km. 21 Jatinangor \\ $\underline{\text { rifqi14006@mail.unpad.ac.id }}$
}

\begin{abstract}
Innovation is the main element to obtain sustainable competitive advantage. Based on the report from Global Innovation Index (GII), Indonesia has ranked on 85th position. The rank is behind neighboring country in Southeast Asia. Indonesia still need to improve their innovation activity. However, there are not much literature that discuss the determinant factors in order to improve innovation activity comprehensively in developing countries, especially Indonesia. The objective of this article is to build a review from previous study and discover the determinant factors that can improve innovation activity. This article use systematic literature review. The result is that there are 7 determinant factors that can improve innovation activity in developing country. Those 7 factors are separated into internal factors and external factors.
\end{abstract}

Keywords: innovation factors, innovation, innovation in developing countries, developing countries, systematic literature review

\begin{abstract}
Abstrak- Inovasi merupakan elemen utama untuk mendapatkan keunggulan kompetitif yang berkelanjutan. Berdasarkan laporan dari Global Innovation Index (GII), Indonesia berada di peringkat ke-85 dan berada di bawah negara-negara di Asia Tenggara lainnya. Indonesia masih perlu untuk meningkatkan aktivitas inovasi. Namun, masih sedikit literatur yang membahas faktor kunci dari inovasi secara komprehensif di negara berkembang, khususnya di Indonesia. Sehingga, dibutuhkan sebuah studi untuk mencari tahu faktor-faktor kunci apa saja yang dapat meningkatkan aktivitas inovasi di negara berkembang, khususnya di Indonesia. Tujuan artikel ini adalah untuk melakukan tinjauan terhadap penelitian terdahulu dan menemukan hal apa saja yang menjadi faktor untuk meningkatkan aktivitas inovasi. Metode yang digunakan adalah tinjauan literatur sistematis. Hasilnya, terdapat 7 faktor kunci yang dapat meningkatkan aktivitas inovasi di negara berkembang. Ketujuh faktor tersebut terbagi menjadi faktor internal dan faktor eksternal.
\end{abstract}

Kata Kunci: Faktor inovasi, Inovasi, Inovasi di negara berkembang, Negara berkembang, Tinjauan literatur sistematis

\section{PENDAHULUAN}

Inovasi memiliki peran untuk mengembangkan aktivitas industri dan performa ekonomi dari sebuah negara [1]. Inovasi juga penting sebagai faktor utama performa organisasi, kesuksesan organisasi, dan membuat organisasi bertahan lebih lama [2]. Selain itu, di tengah lingkungan yang perubahannya cepat, inovasi juga dianggap sebagai elemen utama dari keunggulan kompetitif yang berkelanjutan [3]. Pemerintah di negara berkembang pun sedang mendorong perusahaan dan para pelaku usaha untuk melakukan inovasi dengan tujuan menambah lapangan pekerjaan [4]. Bahkan, inovasi tidak hanya menarik perhatian pemerintah dan pelaku usaha, inovasi yang perannya tidak terbantahkan lagi di dalam perkembangan dunia bisnis saat ini, menarik minat peneliti untuk meneliti di bidang inovasi [5].

Bagaimanakah kondisi inovasi di Indonesia? Sebuah laporan Global Innovation Index (GII) dikeluarkan oleh Cornell University, INSEAD, dan World Intellectual Property Organization (WIPO) untuk mengukur tingkat inovasi sebuah negara dari aspek institusi pemerintahan, kualitas sumber daya manusia dan riset, infrastruktur, kemajuan pasar, kemajuan bisnis, keluaran pengetahuan dan teknologi, serta keluaran kreativitas [6]. Pada laporan GII tahun 2018 dan 2019, Indonesia berada di peringkat ke-85 dari 129 negara [6]. Peringkat tersebut berada di bawah negara-negara di Asia Tenggara seperti Singapura, Malaysia, Vietnam, Thailand, Filipina, dan Brunei Darussalam. Berdasarkan hasil tersebut, Indonesia perlu menaruh perhatian dan meningkatkan aktivitas inovasi.

Untuk meningkatkan aktivitas inovasi, perlu ditelusuri terlebih dahulu faktor-faktor penentu yang membuat aktivitas inovasi itu tercipta [7]. Literatur yang berfokus untuk mencari faktor kunci dari sebuah aktifitas inovasi masih sedikit, terutama di Indonesia yang merupakan salah satu negara berkembang [8].

Oleh sebab itu, dibutuhkan tinjauan literatur sistematis untuk mencari tahu faktor-faktor penentu yang dapat meningkatkan aktivitas inovasi di negara berkembang. Hal tersebut menjadi tujuan dari artikel ini dibuat. Selain itu, artikel ini juga memiliki tujuan untuk menambah kontribusi terhadap ilmu pengetahuan mengenai inovasi. 
Struktur dari artikel ini adalah sebagai berikut. Tahap pertama, akan dijelaskan mengenai definisi dari inovasi. Setelah itu, akan ada penjelasan mengenai metode yang digunakan dan tahapan untuk mengumpulkan data. Lalu penjelasan mengenai temuan dan hasil sintesis dari tinjauan literatur yang sudah dilakukan. Ditutup dengan kesimpulan, implikasi, dan rekomendasi berdasarkan temuan dan sintesis.

\section{KAJIAN PUSTAKA}

\section{Inovasi}

Inovasi itu sendiri merupakan implementasi yang baru ataupun implementasi yang sangat berpengaruh terhadap sebuah produk barang dan jasa, atau merupakan sebuah proses, metode pemasaran yang baru, atau sebuah metode baru yang dikembangkan oleh organisasi [9]. Hal tersebut senada dengan definisi inovasi yang dikembangkan oleh Joseph Alois Schumpeter, seseorang yang dikenal sebagai "prophet of innovation" [10]. Schumpeter juga dikenal sebagai ekonomis terbaik di paruh pertama abad ke-20 [11]. Menurut Schumpeter, inovasi adalah kombinasi dari pengetahuan dan proses yang menghasilkan sebuah ide baru dan digunkan untuk komersialisasi [5], [12].

\section{METODE PENELITIAN}

Penelitian ini menggunakan metode tinjauan literatur sistematis. Tujuan dari metode ini adalah untuk mengumpulkan sebanyak mungkin studi ataupun penelitian terdahulu yang relevan dengan topik penelitian [13]. Tinjauan literatur sistematis dilakukan dengan mengadopsi prinsip-prinsip:

1. A Dilakukan secara detail dengan tujuan untuk meminimalisir bias [14].

2. Tahapan-tahapan yang dilakukan dijelaskan secara detail dan akurat untuk membuat tinjauan literatur sistematis menjadi transparan [15].

3. Fokus terhadap kata kunci ataupun topik yang akan ditinjau [16].

4. Memiliki cakupan basis data elektronik yang luas [17].

5. Melakukan sintesis, yaitu membandingkan dan menghubungkan temuan dari beberapa penelitian terdahulu [17].

Untuk memulai melakukan tinjauan literatur sistematis, perlu ditentukan terlebih dahulu basis data elektronik yang akan digunakan. Terdapat beberapa pilihan basis data elektronik seperti ProQuest, Gale, EBSCO, dan Ovid [18], [19]. Sebuah pencarian pada ketiga basis data tersebut dilakukan dan ditemukan bahwa EBSCO memiliki pilihan subyek yang lebih banyak dibandingkan dengan Ovid dan ProQuest [19].
EBSCO juga cenderung menawarkan judul studi yang lebih banyak dibandingkan dengan Gale dan ProQuest [20]. Selain itu, EBSCO juga lebih agresif dalam menambah judul studi baru beberapa tahun terakhir [20]. Studi lain dilakukan oleh Blessinger dan Olle untuk kembali membandingkan basis data elektronik. Hasil yang diperoleh adalah EBSCO memiliki basis data yang sudah terindeks dan memiliki artikel teks lengkap lebih banyak 19\% dari ProQuest dan 29\% lebih banyak dari Gale, meskipun ProQuest menawarkan kemampuan pencarian bahasa yang lebih intuitif [21]. Dapat disimpulkan bahwa EBSCO memiliki cakupan basis data yang lebih luas dibandingkan dengan Gale, ProQuest, dan Ovid. Sehingga, tinjauan literatur sistematis ini menggunakan EBSCO sebagai basis data elektronik karena sesuai dengan prinsip untuk melakukan tinjauan literatur sistematis yang dikemukakan oleh Thorpe et al., 2015, yaitu memiliki cakupan basis data elekronik yang luas.

Tahapan tinjauan literatur sistematis yang dilakukan adalah sebagai berikut:

1. Melakukan pencarian dengan kata kunci Innovation activities dan diperoleh 452.450 basis data

2. Penambahan kata kunci Determinants sehingga diperoleh 49.890 basis data

3. Dilakukan penyaringan hanya untuk studi yang dilakukan dalam bahasa inggris sehingga diperoleh 41.424 basis data

4. Dilakukan penyaringan kembali untuk memperoleh studi yang termasuk dalam kategori jurnal sehingga diperoleh 38.379 basis data

5. Dilakukan penyaringan kembali untuk memperoleh basis data yang diterbitkan dari tahun 2009 - 2019 dan hasilnya diperoleh 29.034 basis data

6. Dilakukan penyaringan kembali untuk mengambil basis data yang memiliki subyek Developing Country dan memperoleh 270 basis data.

7. Basis data yang sudah diperoleh ditinjau kembali dari sisi judul, abstrak, dan kata kunci.

8. Setelah ditinjau kembali, ditemukan basis data yang sesuai dengan topik artikel ini sejumlah 19 studi yang relevan membahas topik faktor penentu untuk meningkatkan aktivitas inovasi.

9. Seluruh studi ditinjau kembali dari sisi isi untuk dilakukan sintesis dan menemukan faktor-faktor penentu yang dapat meningkatkan aktivitas inovasi. 


\section{HASIL DAN PEMBAHASAN}

Setelah dilakukan tinjauan literatur sistematis, dari 19 studi yang relevan membahas faktor penentu untuk meningkatkan inovasi, terdapat 1 studi yang meneliti institusi perguruan tinggi/universitas, 2 studi yang meneliti inovasi sebuah negara, dan 16 studi yang menggunakan objek perusahaan/organisasi. Faktorfaktor yang dapat meningkatkan aktivitas inovasi terbagi menjadi 2 bagian, yaitu faktor internal dan faktor eksternal. Namun, perusahaan yang lebih bergantung kepada sumber daya eksternal dan kurang memperhatikan kondisi internal cenderung lebih tidak inovatif dibandingkan dengan perusahaan yang lebih aktif dan bergantung untuk menggunakan sumber daya internal [4]. Berikut adalah hasil sintesis dari studi tinjauan literatur sistematis artikel ini.

Tabel 1. Hasil sintesis faktor yang dapat mempengaruhi inovasi

\begin{tabular}{|c|c|c|}
\hline No & Faktor & Penulis (Tahun) \\
\hline \multicolumn{3}{|c|}{ Faktor Internal } \\
\hline 1. & $\begin{array}{l}\text { Karakter pemilik dan } \\
\text { pimpinan perus- } \\
\text { ahaan/organisasi }\end{array}$ & $\begin{array}{l}\text { Daksa et al. (2018), Ge- } \\
\text { breeyesus (2014), Dotun } \\
\text { (2015), Al-husseini \& } \\
\text { Elbeltagi (2016), Jaskyte } \\
(2015)\end{array}$ \\
\hline 2. & $\begin{array}{l}\text { Kegiatan pelatihan } \\
\text { dan pengembangan } \\
\text { pegawai/anggota or- } \\
\text { ganisasi }\end{array}$ & $\begin{array}{l}\text { Daksa et al. (2018), Abdu } \\
\& \text { Jibir (2018), Beyene, } \\
\text { Shi, \& Wu (2016), Nam } \\
\text { et al. (2017), Gebreeye- } \\
\text { sus (2014), Egbetekun, } \\
\text { Atta-ankomah, \& Jegede } \\
\text { (2016), Uden, Knoben, \& } \\
\text { Vermeulen (2017), Dotun } \\
\text { (2015), Hadhri, } \\
\text { Aravnitis, \& Hadhri } \\
\text { (2016), Khalifa (2015) }\end{array}$ \\
\hline No & Faktor & Penulis (Tahun) \\
\hline 3. & $\begin{array}{l}\text { Kepedulian dan in- } \\
\text { vestasi yang dil- } \\
\text { akukan untuk aktivi- } \\
\text { tas Research \& De- } \\
\text { velopment }(R \& D)\end{array}$ & $\begin{array}{l}\text { Daksa et al. (2018), Abdu } \\
\text { \& Jibir (2018), Beyene et } \\
\text { al. (2016), Nam et al. } \\
\text { (2017), Egbetokun et al. } \\
\text { (2016), Mahendra et al. } \\
\text { (2015), Dotun (2015), } \\
\text { Ghazal \& Zulkhibri } \\
\text { (2015), Grovermann, } \\
\text { Wossen, Muller, \& Nich- } \\
\text { terlein (2019), Hadhri et } \\
\text { al. (2016) }\end{array}$ \\
\hline 4. & $\begin{array}{l}\text { Memiki pekerja tetap } \\
\text { dengan tingkat pen- } \\
\text { didikan yang tinggi }\end{array}$ & $\begin{array}{l}\text { Daksa et al. (2018), Ge- } \\
\text { breeyesus (2014), Egbe- } \\
\text { tokum et al. (2016), Uden } \\
\text { et al. (2017), Dotun }\end{array}$ \\
\hline
\end{tabular}

\begin{tabular}{|c|c|c|}
\hline & & $\begin{array}{l}\text { (2015), Ghazal } \\
\text { Zulkhibri (2015) }\end{array}$ \\
\hline 5. & $\begin{array}{l}\text { Status sebagai ekspor- } \\
\text { tir dan memiliki hub- } \\
\text { ungan dengan entitas } \\
\text { di luar negeri }\end{array}$ & $\begin{array}{l}\text { Daksa et al. (2018), Abdu } \\
\& \quad \text { Jibir } \quad(2018), \text { Eg- } \\
\text { ebtokun et al. (2016), Do- } \\
\text { tun (2015), Hadhri et al. } \\
(2016)\end{array}$ \\
\hline 6. & Ukuran perusahaan & $\begin{array}{l}\text { Daksa et al. (2018), Abdu } \\
\& \text { Jibir (2018), Beyene et } \\
\text { al. (2016), Gebreeyesus } \\
\text { (2014), Egbetokun et al. } \\
(2016)\end{array}$ \\
\hline \multicolumn{3}{|c|}{ Faktor Eksternal } \\
\hline 1. & $\begin{array}{l}\text { Akses untuk } \\
\text { mendapatkan bantuan } \\
\text { keuangan/tambahan } \\
\text { modal }\end{array}$ & $\begin{array}{l}\text { Mahendra et al. (2015), } \\
\text { Dotun (2015), Grover- } \\
\text { mann }(2016)\end{array}$ \\
\hline 2. & $\begin{array}{l}\text { Performa dan regulasi } \\
\text { pemerintah }\end{array}$ & $\begin{array}{l}\text { Mahendra et al. (2015), } \\
\text { Dotun (2015), Balalaeva } \\
\text { (2015), Fiore, Grisorio, \& } \\
\text { Prota (2011), Ghazal \& } \\
\text { Zulkhibri (2015), Hadhri } \\
\text { et al. (2016), Karo \& Kat- } \\
\text { tel (2011), Pinto, \& San- } \\
\text { tos Pereira (2013) }\end{array}$ \\
\hline
\end{tabular}

Sumber: Data diolah

\section{Karakter Pemilik dan Pimpinan Perusahaan/Or- ganisasi}

Karakteristik dan kapasitas dari pemilik perusahaan dan pengusaha mempengaruhi inovasi yang terjadi di perusahaan [4], [22]. Karakteristik dari manajer pun mempunyai pengaruh terhadap aktivitas inovasi [23]. Jadi bukan hanya karakter dari pemilik perusahaan dan pengusaha yang dapat meningkatkan aktivitas inovasi, tetapi karakter dari manajer atau pimpinan di perusahaan juga memiliki dampak untuk meningkatkan aktivitas inovasi. Selain mempengaruhi inovasi, karakteristik dari pemilik perusahaan juga mempengaruhi pertumbuhan perusahaan [24]. Karakteristik yang dimaksud adalah memiliki kepemimpinan yang transformasional [25]. Kepemimpinan yang transformasional ini dapat dilihat dari pengaruh yang diberikan, dapat memberikan motivasi yang menginspirasi, mampu mendorong timnya untuk mencoba hal-hal baru dan membahas kembali sebuah permasalahan untuk dicari solusi yang baru, serta dapat membangun hubungan yang personal kepada anak buahnya, salah satunya dengan cara memberikan apresiasi terhadap pekerjaan anak buahnya [25]. Tidak ada penelitian yang menunjukan bahwa karakter pimpinan perusahaan memberikan dampak yang buruk terhadap aktivitas inovasi. 


\section{Kegiatan Pelatihan dan Pengembangan Pega- wai/Anggota Organisasi}

Kegiatan pelatihan untuk pegawai ataupun anggota organisasi dapat meningkatkan aktivitas inovasi. Bahkan aktivitas pelatihan non-formal pun dapat meningkatkan aktivitas inovasi [23]. Sehingga, seluruh bentuk pelatihan dapat meningkatkan aktivitas inovasi. Bahkan, kombinasi yang tepat dalam aktivitas peningkatan kualitas pegawai atau anggota organisasi lebih dapat meningkatkan inovasi dibandingkan anggaran $R \& D$ yang tinggi [26].

\section{Kepedulian dan Investasi yang Dilakukan untuk Aktivitas Research \& Development (R\&D)}

Proporsi anggaran yang besar untuk $R \& D$ dapat meningkatkan aktivitas inovasi. Bahkan minimnya anggaran $R \& D$ menjadi penyebab turunnya aktivitas inovasi [27]. Meskipun demikian, istilah semakin besar anggaran $R \& D$, maka semakin besar juga aktivitas inovasi yang terjadi tidak sepenuhnya benar. Dibutuhkan persentase yang tepat dari anggaran $R \& D$ untuk meningkatkan aktivitas inovasi dan hanya $R \& D$ yang bersifat terapan dan pengembangan yang dapat meningkatkan inovasi [28].

\section{Memiliki Pekerja Tetap dengan Tingkat Pendidi- kan yang Tinggi}

Jumlah pekerja atau anggota organisasi yang memiliki pendidikan tinggi berpengaruh positif terhadap aktivitas inovasi [4], [23], [24], [29]. Namun, pendidikan yang tinggi tidak memiliki dampak yang signifikan terhadap inovasi [28]. Hal tersebut dikarenakan lulusan perguruan tinggi tidak sepenuhnya memiliki kemampuan yang dibutuhkan oleh industri [28]. Meskipun tingkat pendidikan yang tinggi masih mempunyai dampak terhadap inovasi, dampak yang diberikan tidaklah signifikan. Lebih baik untuk perusahaan atau anggota organisasi jika memiliki pegawai dengan kemampuan dan keterampilan yang tinggi dan dibutuhkan oleh industri [28], [30]. Sehingga, memiliki pekerja atau anggota organisasi yang berpendidikan tinggi tidak menjadi faktor kunci dari meningkatnya aktivitas inovasi.

\section{Status Sebagai Eksportir dan Memiliki Hubungan dengan Entitas di Luar Negeri}

Perusahaan yang melakukan interaksi dengan pihak mancanegara juga memiliki pengaruh yang positif terhadap meningkatnya output inovasi perusahaan [29]. Interaksi yang dimaksud dapat berupa kolaborasi yang dilakukan dengan pihak luar negeri [23]. Walaupun berpengaruh positif terhadap peningkatan aktivitas inovasi, pengaruh yang diberikan dari interaksi dan kolaborasi yang dilakukan dengan pihak asing tidaklah signifikan. Hal yang berpengaruh secara positif dan signifikan terhadap aktivitas inovasi adalah aktivitas eksport yang dilakukan oleh perusahaan. Perusahaan yang memiliki status sebagai eksportir memiliki pengaruh yang positif dan signifikan terhadap kecenderungan perusahaan untuk melakukan inovasi [1], [30].

\section{Ukuran Perusahaan}

Ukuran perusahaan menjadi salah satu faktor yang mempengaruhi perkembangan inovasi [1], [27], [29]. Ukuran perusahaan yang besar dapat mendorong meningkatnya aktivitas inovasi [4]. Bahkan ukuran perusahaan memberikan efek yang kuat terhadap aktivitas inovasi [24].

\section{Akses untuk Mendapatkan Bantuan Keu- angan/Tambahan Modal}

Sulitnya akses keuangan yang didapatkan oleh perusahaan berdampak pada sulitnya inovasi yang dilakukan oleh perusahaan [8], [23]. Dukungan finansial menjadi salah satu faktor penentu untuk meningkatkan inovasi di negara yang kurang berkembang [31]. Sulitnya akses untuk mendapatkan bantuan keuangan atau tambahan modal berdampak pada berkurangnya akses ke R\&D sehingga membuat perusahaan sulit untuk berinovasi [8]. Selain untuk menambah anggaran untuk R\&D, bantuan keuangan atau tambahan modal ini juga dapat dimanfaatkan oleh perusahaan untuk melakukan pelatihan pegawainya yang akan berdampak terhadap meningkatnya aktivitas inovasi. Dapat dikatakan bahwa akses untuk mendapatkan bantuan keuangan atau tambahan modal akan berdampak pada kurangnya akses yang dapat dilakukan perusahaan untuk melakukan R\&D dan pelatihan pegawai. Aktivitas R\&D dan pelatihan pegawailah yang menjadi faktor kunci untuk meningkatkan aktivitas inovasi, bukan akses perusahaan untuk mendapatkan bantuan keuangan atau tambahan modal.

\section{Performa dan Regulasi Pemerintah}

Dukungan dari pemerintah menjadi salah satu faktor yang berpengaruh terhadap peningkatan aktivitas inovasi [23], [30]. Dukungan yang dimaksud dapat berupa kebijakan publik yang mendorong organisasi untuk melakukan inovasi [32], [33]. Bahkan, kebijakan dan regulasi yang mendukung terciptanya aktivitas 
inovasi menjadi faktor krusial untuk mendorong peningkatan aktivitas inovasi [33]. Dukungan dari segi kebijakan juga dapat berupa kebijakan untuk menarik FDI (Foreign Direct Investment) yang dapat meningkatkan output inovasi. Bahkan, saat sebuah organisasi sudah mempunyai kekuatan politik, organisasi tersebut dapat menghambat aktivitas inovasi yang dilakukan oleh kompetitor [34]. Namun, sebelum fokus terhadap kebijakan publik, kebijakan mengenai inovasi perlu difokuskan terlebih dahulu untuk pengembangan institusi terkait dan mengembangkan kapasitasnya untuk menerapkan sistem inovasi secara menyeluruh [35].

\section{KESIMPULAN DAN SARAN}

Setelah dilakukan tinjauan literatur sistematis, terdapat enam faktor internal dan dua faktor eksternal yang menjadi faktor untuk meningkatkan aktivitas inovasi. Dari semua faktor tersebut, terdapat beberapa faktor yang bukan merupakan faktor kunci yang dapat meningkatkan aktivitas inovasi. Salah satu faktornya adalah faktor jumlah pegawai atau anggota organisasi yang memiliki pendidikan tinggi. Meskipun faktor tersebut memberikan dampak positif terhadap peningkatan aktivitas inovasi, tetapi dampaknya tidaklah signifikan dan lebih baik untuk memiliki pegawai yang memiliki kemampuan dan keterampilan yang memadai dibandingkan pegawai yang memiliki latar belakang pendidikan yang tinggi.

Dapat disimpulkan bahwa terdapat tujuh faktor kunci yang dapat meningkatkan aktivitas inovasi di negara berkembang. Ketujuh faktor kunci tersebut adalah:

1. Memiliki pimpinan perusahaan yang mempunyai karakter kepemimpinan yang transformasional.

2. Mengadakan pelatihan kemampuan dan keterampilan pegawai atau anggota organisasi, baik itu secara formal maupun non-formal.

3. Mempunyai persentase anggaran $R \& D$ yang tidak sedikit, namun tepat sesuai dengan kebutuhan.

4. Memiliki status sebagai eksportir.

5. Ukuran perusahaan.

6. Akses untuk mendapatkan bantuan keuangan atau tambahan modal.

7. Performa dan regulasi pemerintah.

Perusahaan, organisasi, ataupun pemerintah di negara berkembang dapat memfokuskan diri untuk mengembangkan ketujuh faktor tersebut untuk meningkatkan aktivitas inovasi yang akan meningkatkan performa ekonomi secara menyeluruh dan mendapatkan keunggulan kompetitif yang berkelanjutan.
Namun, artikel ini mempunyai batasan, yaitu memiliki batasan konteks dan hanya mencari faktor kunci yang meningkatkan aktivitas inovasi negara berkembang. Penelitian selanjutnya dapat mencari faktor kunci untuk meningkatkan aktivitas inovasi dari negara maju yang dapat diimplementasikan oleh negara berkembang. Penelitian selanjutnya dapat mencari turunan atau kegiatan teknis dari tujuh faktor kunci untuk meningkatkan aktivitas inovasi di negara berkembang.

\section{REFERENSI}

[1] M. Abdu and A. Jibir, "Determinants of firms innovation in Nigeria," Kasetsart J. Soc. Sci., vol. 39, no. 3, pp. 448-456, 2018, doi: 10.1016/j.kjss.2017.07.006.

[2] N. Anderson and K. Potočnik, "Innovation and Creativity in Organizations: A State-of-theScience Review, Prospective Commentary, and Guiding Framework," J. Manage., vol. 40, no. 5, pp. 1297-1333, 2014, doi: $10.1177 / 0149206314527128$.

[3] T. H. Nam, N. P. Tuan, and N. Van Minh, "Critical Successful Factors for Innovation in Vietnamese Firms," J. Ind. Eng. Manag., vol. 10, no. 3, pp. 522-544, 2017.

[4] M. D. Daksa, M. A. Yismaw, S. D. Lemessa, and S. K. Hundie, "Enterprise innovation in developing countries: an evidence from Ethiopia," J. Innov. Entrep., vol. 7, no. 1, 2018, doi: 10.1186/s13731-018-0085-4.

[5] E. Suroso and Y. Azis, "Defining Mainstreams Of Innovation: A Literature Review," 2015, doi: 10.2991/iceb-15.2015.55.

[6] Cornell University, INSEAD, and WIPO, “Global Innovation Index 2019," 2019.

[7] N. A. Hamdani, S. Nugraha, and P. Purnamasari, "Conceptual Framework of Innovation Strategy in SMEs," BIEJ Bus. Innov. Entrep. J., vol. 2, no. 2, pp. 115-119, 2020.

[8] E. Mahendra, U. Zuhdi, and R. Muyanto, "Determinants of Firm Innovation in Indonesia : The Role of Institutions and Access to Finance Determinants of Firm Innovation in Indonesia : The Role of Institutions and Access to Finance," Econ. Financ. Indones., vol. 61, 
no. April 3, pp. 149-179, 2015, doi: 10.7454/efi.v61i3.512.

[9] OECD, "The Measurement of Scientific and Technological Activities: Guidelines for Collecting and Interpreting Innovation Data: Oslo Manual, Third Edition" prepared by the Working Party of National Experts on Scientific and Technology Indicators," 2005.

[10] A. Croitoru, "Schumpeter, J.A., 1934 (2008), The Theory of Economic Development: An Inquiry into Profits, Capital, Credit, Interest and the Business Cycle, translated from the German by Redvers Opie, New Brunswick (U.S.A) and London (U.K.): Transaction Publishers. A re," J. Comp. Res. Anthropol. Sociol., vol. 3, no. 2, pp. 137-148, 2012.

[11] K. Śledzik, "SCHUMPETER' S VIEW ON INNOVATION AND ENTREPRENEURSHIP," SSRN Electron. J., no. April, 2013, doi: 10.2139/ssrn.2257783.

[12] J. A. Schumpeter, The Theory of Economic Development. Cambridge, MA.: Harvard University Press, 1934.

[13] R. Thorpe, R. Holt, and A. Macpherson, "Using knowledge within small and medium-sized firms : A systematic review of the evidence," Int. J. Manag. Rev., vol. 7, no. 4, pp. 257-281, 2005, doi: 10.1111/j.1468-2370.2005.00116.x.

[14] D. Tranfield, D. Denyer, and P. Smart, "Towards a Methodology for Developing Evidence-Informed Management Knowledge by Means of Systematic Review* Introduction: the need for an evidence- informed approach," Br. J. Manag., vol. 14, pp. 207-222, 2003.

[15] D. Denyer and A. Neely, "Introduction to special issue: Innovation and productivity performance in the UK," Int. J. Manag. Rev., vol. 5-6, no. 3-4, pp. 131-135, 2004, doi: 10.1111/j.1460-8545.2004.00100.x.

[16] P. Luke, R. Maxine, M. Kamal, D. David, and N. Andy, "Networking and innovation: a systematic review of the evidence," Int. J. Manag. Rev., vol. 5-6, no. 3-4, pp. 137-168, 2004.

[17] R. Thorpe, R. Holt, A. Macpherson, and L. Pittaway, "Using knowledge within small and medium-sized firms: A systematic review of the evidence," Int. J. Manag. Rev., vol. 7, no. 4, pp. 257-281, 2005, doi: 10.1111/j.14682370.2005.00116.x.

[18] Y. Zhang and D. Su, "Overview and Evaluation of Selected General Business Databases," J. Bus. Financ. Librariansh., vol. 23, no. 1, pp. 103-111, 2018, doi: 10.1080/08963568.2018.1449510.

[19] M. M. Allison, "Comparison of CINAHL $₫$ via EBSCOhost $\AA$, Ovid $\AA$, and ProQuest $\AA$," J. Electron. Resour. Med. Libr., vol. 3, no. 1, 2006, doi: 10.1300/J383v03n01.

[20] K. Blessinger and M. Olle, "Content analysis of the leading general academic databases," Libr. Collect. Acquis. Tech. Serv., vol. 28, no. 3, pp. 335-346, 2004, doi: 10.1016/j.lcats.2004.05.001.

[21] K. Blessinger and M. Olle, "Comparison of Three Primary Aggregator Databases," Ser. Libr. From Print. Page to Digit. Age, no. May 2015, pp. 37-41, 2008, doi: $10.1300 / \mathrm{J} 123 \mathrm{v} 45 \mathrm{n} 01$.

[22] K. Jaskyte, "Board of Directors and Innovation in Nonprofit Organizations Model : Preliminary Evidence from Nonprofit Organizations in Developing Countries," Int. Soc. Third-Sector Res., pp. 1920-1943, 2015, doi: 10.1007/s11266-014-9505-7.

[23] F. O. Dotun, "the Key Determinants of Innovation in Small and Medium Scale Enterprises in Southwestern Nigeria," Eur. Sci. J., vol. 11, no. 13, pp. 465-480, 2015.

[24] M. Gebreeyesus, "Innovation and microenterprises growth in Ethiopia," $U N U$ WIDER, no. May, 2014.

[25] S. Al-husseini and I. Elbeltagi, "Transformational leadership and innovation: a comparison study between Iraq' s public and private higher education," Stud. High. Educ., vol. 41, no. 1, pp. 159-181, 2016.

[26] A. Van Uden, J. Knoben, and P. Vermeulen, "Human capital and innovation in Sub-Saharan countries : a firm-level study," Innovation, vol. 19 , no. 2, pp. 103-124, 2017, doi: 10.1080/14479338.2016.1237303.

[27] K. T. Beyene, C. S. Shi, and W. W. Wu, "THE IMPACT OF INNOVATION STRATEGY ON 
ORGANIZATIONAL LEARNING AND INNOVATION," South African J. Ind. Eng., vol. 27, no. 1, pp. 125-136, 2016.

[28] R. Ghazal and M. Zulkhibri, "Determinants of innovation outputs in developing countries Evidence from panel data negative," J. Econ. Stud., vol. 42, no. 2, pp. 237-260, 2015, doi: 10.1108/JES-01-2013-0016.

[29] A. Egbetokun, R. Atta-ankomah, and O. Jegede, "Firm-level innovation in Africa: overcoming limits and constraints," Innov. Dev., vol. 6, no. 2, pp. 161-174, 2016, doi: 10.1080/2157930X.2016.1224619.

[30] W. Hadhri, R. Arvanitis, and W. Hadhri, "DETERMINANTS OF INNOVATION ACTIVITIES IN SMALL AND OPEN ECONOMIES : THE LEBANESE BUSINESS SECTOR DETERMINANTS OF INNOVATION ACTIVITIES IN SMALL AND OPEN ECONOMIES : THE LEBANESE," J. Innov. Econ. Manag., vol. 3, no. 21, pp. 77-107, 2016.

[31] C. Grovermann, T. Wossen, A. Muller, and K. Nichterlein, "Eco-efficiency and agricultural innovation systems in developing countries : Evidence from macro-level analysis," PLoS
One, vol. 14, no. 4, pp. 1-17, 2019.

[32] A. Fiore, M. J. Grisorio, and F. Prota, "Regional Innovation Systems: Which Role for Public Policies and Innovation Agencies? Some Insights from the Experience of an Italian Region," Eur. Plan. Stud., vol. 19, no. 8, 2011, doi: 10.1080/09654313.2011.586173.

[33] H. Pinto and T. Santos Pereira, "Efficiency of Innovation Systems in Europe: An Institutional Approach to the Diversity of National Profiles," Eur. Plan. Stud., vol. 21, no. 6, pp. 755-779, 2013 doi: 10.1080/09654313.2012.665033.

[34] D. Balalaeva, "Political Competition , Agenda Power, and Incentives to Innovate: An Empirical Examination of Vested-Interest Theory," Rev. Policy Res., vol. 32, no. 4, pp. 413-443, 2015.

[35] E. Karo and R. Kattel, "Should "“ open innovation ", change innovation policy thinking in catching- up economies? Considerations for policy analyses," Eur. J. Soc. Sci. Res., vol. 24, no. June, pp. 173-199, 2011, doi: 10.1080/13511610.2011.586496. 